\title{
PUMA mediated afatinib-induced apoptosis in glioma cells
}

\author{
Rongzhong $\mathrm{Lu}^{1}$, Xinyue Sun², Yaping Ma³, Rong Wang ${ }^{3}$
}

${ }^{1}$ Zibo Central Hospital, China

${ }^{2}$ Medical College of Yan'an University, China

${ }^{3}$ Affiliated Hospital of Hubei University of Arts and Science, Xiangyang Central

Hospital, China

Submitted: 21 December 2019; Accepted: 1 April 2020

Online publication: 5 April 2021

Arch Med Sci 2022

DOI: https://doi.org/10.5114/aoms/119970

Copyright $\odot 2022$ Termedia \& Banach

\section{Abstract}

Introduction: Afatinib exhibits a tumor-inhibiting effect in different cancers by inducing apoptosis; however, its pro-apoptosis role in glioma cells is still not fully understood.

Material and methods: In the current study, two glioma cell lines (U373-MG and $U 87-M G$ ) were treated with afatinib to measure their tolerance for afatinib-triggered cell death and apoptosis.

Results: We found that afatinib treatment repressed both growth and proliferation and induced apoptosis in glioma cells. Moreover, it increased the expression of pro-apoptotic p53-upregulated modulator of apoptosis (PUMA). The influence of PUMA on afatinib-triggered apoptosis was assessed by PUMA overexpression and knockdown in glioma cell lines. PUMA overexpression resulted in increased sensitivity of glioma cell lines toward afatinib, whereas its knockdown abated the effect of afatinib on apoptosis. Similarly, the in vivo potency of afatinib on U373-MG xenograft tumors in wild type (WT) and PUMA knockdown nude mice was measured. Afatinib treatment reduced the weight and volume of WT xenograft tumors but did not have the same effect on PUMA knockdown xenograft tumors. Afatinib also induced significant cell death and apoptosis in WT xenograft tumors but not in PUMA knockdown xenograft tumors.

Conclusions: Afatinib induces apoptosis in glioma cells by mediating PUMA expression. This study warrants further investigation into the mechanism of afatinib in glioblastoma treatment.

Key words: glioma, afatinib, PUMA, apoptosis, mouse.

\section{Introduction}

Glioma is a type of major neural malignant tumor with an average survival of 12-15 months in people who undergo surgery, chemotherapy, and radiation treatment [1]. Gliomas arise from malignant transformation of glial cells and can be subdivided into astrocytomas, oligodendrogliomas, ependymomas, and mixed gliomas according to their clinical and pathological features [2]. Despite the high toxicities of existing treatment methods, most patients with brain cancer exhibit tumor recurrence because of incompatibility with radio- and chemo-therapy [3-5]. However, current chemotherapeutic methods have exhibited unfavorable efficacy in treating these tumors; therefore, the development of additional treatment methods is necessary. It is imperative to discover new therapeutic tools that directly act on the molecules that are altered in the malignancy.

\author{
Corresponding author: \\ Yaping $\mathrm{Ma}$ \\ Affiliated Hospital of Hubei \\ University of Arts \\ and Science \\ Xiangyang Central Hospital, \\ China \\ E-mail: myp105m@163.com
}


Afatinib has been approved by the Food and Drug Administration due to its inhibitory effect on EGFR, HER2, HER4, and EGFRvIII through an irreversible association with ATP binding sites [6-8]. Several studies have indicated that afatinib, in relation to gemcitabine and cisplatin or pemetrexed and cisplatin, could dramatically increase the progression-free survival (PFS) of patients with EGFR mutant non-small-cell lung cancer (NSCLC) $[9,10]$ and those simultaneously developing brain metastases [11]. Further, afatinib dramatically improved PFS and overall survival (OS) of patients diagnosed with pulmonary squamous cell carcinoma [12]. Afatinib has also been confirmed to cross the blood-brain barrier [13]. Afatinib has a manageable safety profile but limited single-agent activity in unselected recurrent glioblastoma multiforme patients [14]. Interestingly, in another study, afatinib noticeably increased the OS of patient with EGFRvIII- and EGFR-overexpressing recurrent glioma by six times (60 months) [15]. Combinatorial treatment with afatinib and temozolomide significantly inhibited the tumorigenicity of glioblastoma, maintenance of cancer stem cells in vitro, and growth and development of tumor in vivo [16]

p53-upregulated modulator of apoptosis (PUMA), a member of the $\mathrm{Bcl}-2$ homology 3-(BH3)-only subgroup of the $\mathrm{Bcl}-2$ family, may directly regulate p53-relevant apoptosis [17-19]. The PUMA protein is relevant to mitochondria; when overexpressed in diverse cell lines, it could trigger apoptosis before p53 exogenous expression induces apoptosis. Additionally, PUMA can regulate p53-relevant apoptosis and its corresponding pathways. These findings revealed that PUMA plays an essential role in mediating cell apoptosis. In the current study, we administered afatinib to the glioma cells of xenograft tumors to assess its effect on apoptosis induction in vitro and in vivo. Next, we investigated whether PUMA was associated with the pro-apoptosis effect of afatinib in glioma cell lines or xenograft tumor.

\section{Material and methods}

\section{Cell culture}

U373-MG and U87-MG [20] cells, collected from the China Academia Sinica Cell Repository, were maintained in Dulbecco's Modified Eagle Medium (DMEM) containing fetal bovine serum (FBS; 10\%), glutamine $(2 \mathrm{mmol} / \mathrm{l})$, and penicillin and streptomycin $\left(0.1 \mathrm{mg} / \mathrm{ml}\right.$ each) in a $5 \% \mathrm{CO}_{2}$ atmosphere at $37^{\circ} \mathrm{C}$. Cells were transfected using Lipofectamine 2000 (11668030, Thermo Fisher) as per the manufacturer's instructions.

\section{Reagents and drug preparation}

Afatinib (Giotrif, Selleck Chemicals) was diluted with dimethyl sulfoxide (DMSO) to $10 \mathrm{mmol} / \mathrm{l}$ and stored at $-20^{\circ} \mathrm{C}$. For in vitro studies, afatinib was diluted with DMSO to various concentrations $(1,5$, and $10 \mu \mathrm{M})$ and subsequently added to cells in DMEM without serum. For in vivo studies, afatinib was diluted with distilled water to $1.25 \mathrm{mg} / \mathrm{ml}$.

PUMA knockdown shRNA plasmid was purchased from Santa Cruz Biotechnology. PUMA overexpression plasmid was purchased from Addgene. All siRNAs were synthesized by GenePharma. Control siRNA duplexes targeted the sequence 5'-UUC UCC GAA CGU GUC ACG U-3'. PUMA SiRNA duplexes targeted the sequence of 5'-CGG ACG ACC UCA ACG CAC A-3'. Lipofectamine 2000 (Invitrogen) was used for transfection as per the manufacturer's instructions.

\section{Xenograft model in athymic mice and drug treatment}

All animal experiment protocols were approved by our hospital. U373-MG cells and U373-MG cells $\left(1 \times 10^{7}\right)$ with PUMA knockdown were subcutaneously injected to the right flanks of female nude mice, thereby creating tumor xenografts. U373MG tumor-carrying mice were randomly classified into four groups (six mice per group) 5 days after tumor cell inoculation. Next, tumor size was determined and tumor volume (TV) was obtained using the following formula (the unit of parameters was "mm"): TV $=1 / 2\left(\right.$ length $\times$ width $\left.^{2}\right) \mathrm{mm}^{3}$. Optimal TV inhibition percentage (TVI\%) was calculated as 100 - (TV treated/TV control $\times 100)$

The mice were then subjected to afatinib or vehicle treatment $(0.01 \mathrm{~g} / \mathrm{kg}$ body weight) for 5 days per week, for 30 days (the start date was considered day 1). They were executed when in a particularly weak condition.

\section{Western blotting (WB)}

Cells were lysed using a RIPA lysis assay buffer (89901, Thermo Fisher), and the total amount of $100 \mu \mathrm{g}$ of proteins were separated using $10 \%$ SDSPAGE and then transferred onto Immobilon PVDF (0.45 $\mu \mathrm{m})$ membranes, which were successively incubated with primary antibodies for $16 \mathrm{~h}$ and corresponding secondary antibodies for $60 \mathrm{~min}$. The primary and secondary antibodies used in this study were as follows: Rabbit monoclonal anti-Bax antibody (1:2500, 2774S, CST), Mouse monoclonal anti-Bcl-2 antibody (1: 2500, 15071S, CST), Rabbit polyclonal anti-PUMA antibody (1: 1000, ab9643, Abcam), Goat anti-rabbit IgG H\&L (HRP) (1 : 5000, ab205718, Abcam), and Goat anti-mouse IgG H\&L ( 1 : 5000, ab6708, Abcam). The Mouse anti-beta Actin antibody (1:5000, ab8226, Abcam) and the Mouse anti-beta GAPDH antibody (1: 5000, ab8245, Abcam) served as a loading control. The above incubation process was conducted at $4^{\circ} \mathrm{C}$. Blots were visualized using chemiluminescence reagents (15159, Thermo Fisher) and a C-DiGit blot scanner. 


\section{Quantitative polymerase chain reaction (Q-PCR)}

RNA was isolated with TRIzol reagent (15596026, Thermo Fisher), and electrophoresis of the products on $3.5 \%$ agarose gels was performed to validate the specific generation of the expected PCR product. Relative gene expression levels were determined with SYBR Green master mix using qRT-PCR with GAPDH, which is stably expressed among samples, as an internal reference. The PUMA and GAPDH were amplified using the following pairs of primers: PUMA forward 5'-CTG CTG CCC GCT GCC TAC CT-3' and PUMA reverse 5'-CCG CTC GTA CTG TGC GTT GAG-3'; GAPDH forward 5'-AAT CCC ATC ACC ATC TTC C-3' and GAPDH reverse 5'-CAT CAC GCC ACA GTT TCC-3' [21]. Reactions were conducted in triplicate in $0.02 \mathrm{ml}$ of reaction solution in an $\mathrm{ABI} 7500$ Real-Time PCR System. The amplification profile was denatured at $95^{\circ} \mathrm{C}$ for $10 \mathrm{~min}$, followed by 40 cycles of $95^{\circ} \mathrm{C}$ for $15 \mathrm{~s}$ and $60^{\circ} \mathrm{C}$ for $45 \mathrm{~s}$, in which fluorescence was acquired. At the end of the PCR cycles, melting curve analyses were performed. $\triangle \mathrm{Ct}$ was calculated by subtracting the $\mathrm{Ct}$ values of GAPDH from the $\mathrm{Ct}$ values of the gene of interest. $\Delta \Delta \mathrm{Ct}$ was then calculated by subtracting $\Delta \mathrm{Ct}$ of the control from $\Delta \mathrm{Ct}$ of the sample. The $2^{-\Delta \Delta c T}$ method was applied to calculate the copy number of target genes.

\section{Cell proliferation and colony formation assay}

Cell proliferation capacity was evaluated using the CCK-8 assay according to the manufacturer's instructions. Cells were seeded into 96-well plates, CCK-8 $(10 \mu \mathrm{l})$ was added to each well and cells were incubated for a further $2 \mathrm{~h}$ at $37^{\circ} \mathrm{C}$. Optical density (OD) was measured at $450 \mathrm{~nm}$ using an auto-microplate reader (infinite M200, Tecan, Switzerland).

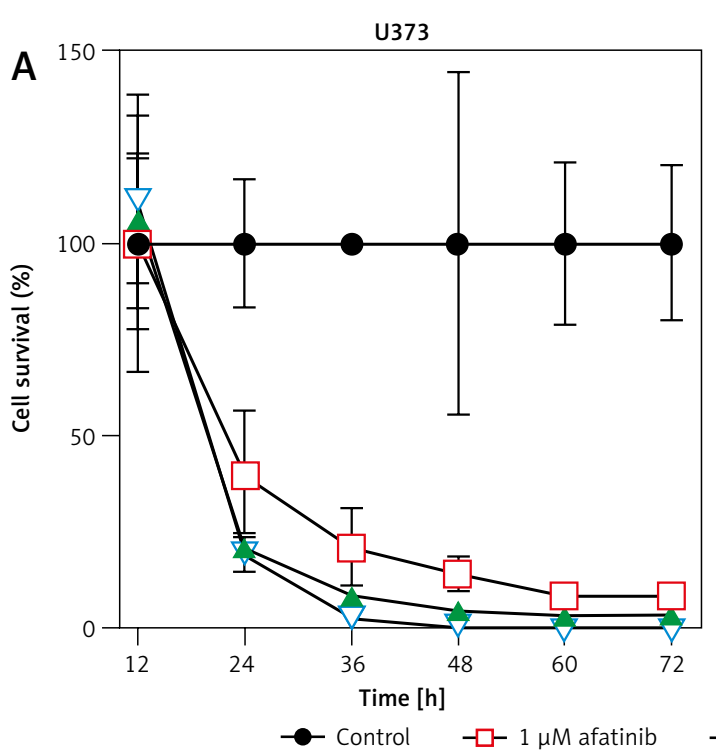

For the colony formation experiment, cells were cultured in 6-well plates and cultured for 7 days. They were then fixed in $4 \%$ formaldehyde for 20 min and stained with $1.0 \%$ crystal violet.

\section{Annexin V-FITC/PI flow cytometry (FC)}

Apoptosis was assessed using the Annexin V-FITC/PI FC (640914, BioLegend) test as previously described [22].

\section{Statistical analysis}

Data were expressed as mean \pm SD. Significant differences among groups were assessed by SPSS software (12.0) using ANOVA and Tukey's test, and between-group differences were analyzed using the $t$-test. Values of $p<0.05$ indicated a significant difference.

\section{Results}

Afatinib-induced inhibition of proliferation and growth of glioma cells

U373 and U87 cells were treated with afatinib at 1,5 , and $10 \mu \mathrm{M}$, based on a previous study in non-small cell lung carcinoma [23]. A Cell Counting Kit-8 (CCK-8) assay indicated that the proliferation rates of $U 373$ and $U 87$ cells significantly decreased owing to afatinib treatment at 36-72 h, depending on the afatinib concentration (Figures $1 \mathrm{~A}, \mathrm{~B}$ ). The colony formation assay indicated that the growth of glioma cells declined after afatinib treatment in a dose-dependent manner (Figures 1 C, D). Altogether, these results indicate that afatinib repressed both the proliferation and growth rates of the glioma cells.

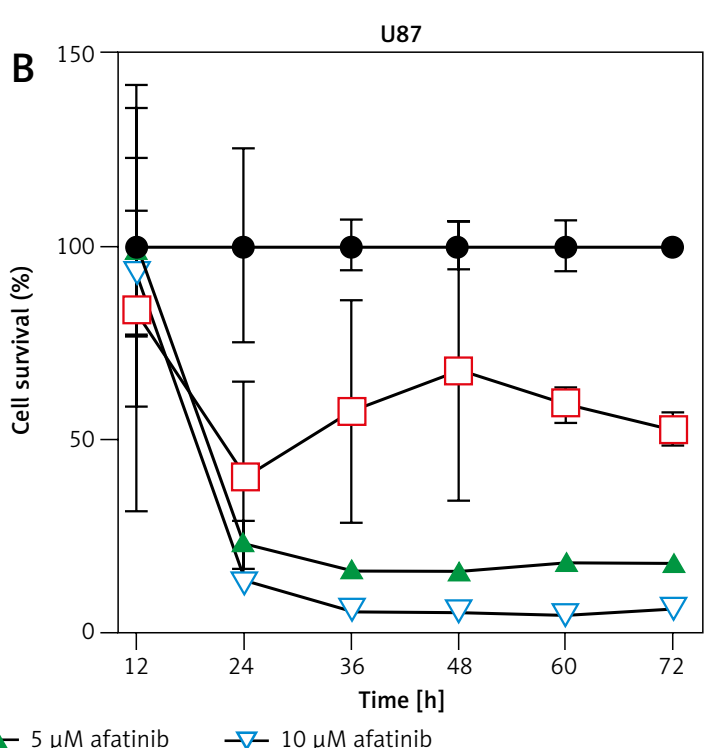

Figure 1. Glioma cell growth and proliferation suppressed by afatinib. U373 and U87 cells were exposed to afatinib of different concentrations $(1,5$, and $10 \mu \mathrm{M})$. A, B - CCK-8 assay reveals that the proliferation rates of the two cell lines significantly decreased when treated with different concentrations of afatinib. 
$\mathrm{C}$
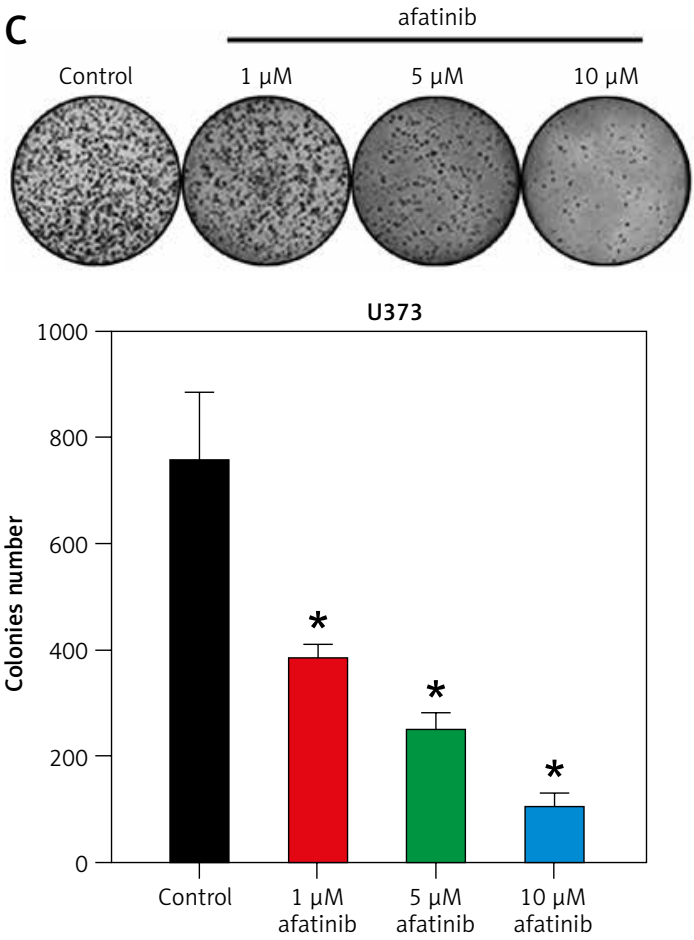

D
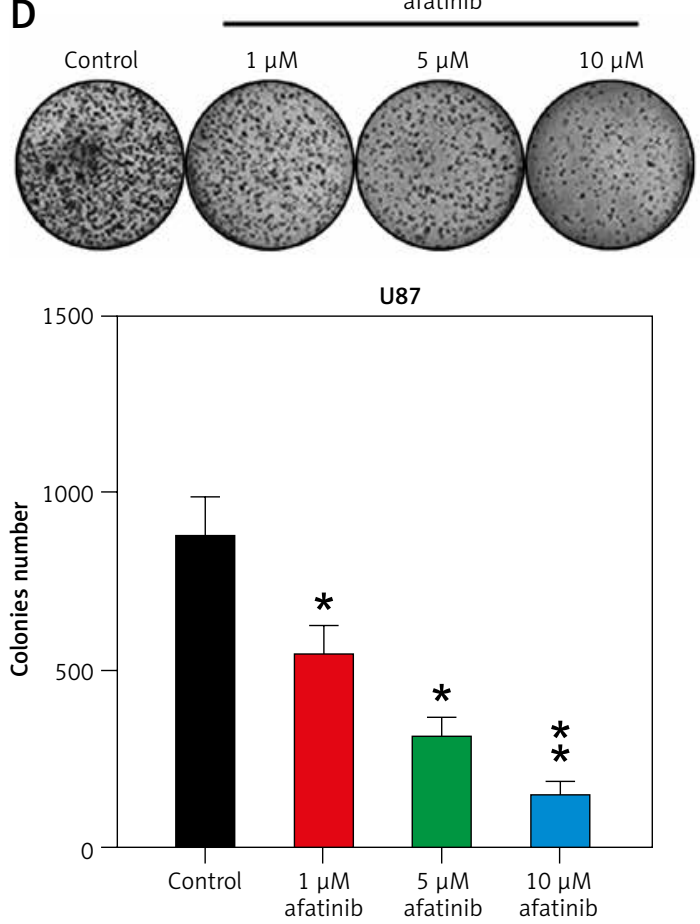

Figure 1. Cont. C, D - Soft agar colony formation assay for glioma cells was used to detect the number of cells at $72 \mathrm{~h}$ after afatinib treatment. $N=3 ;{ }^{*} p<0.05 ;{ }^{* *} p<0.01$ (vs control group)

Effects of afatinib on cell apoptosis and related proteins

To explore how afatinib affects the apoptosis of glioma cells, U373 and U87 cells were treated with
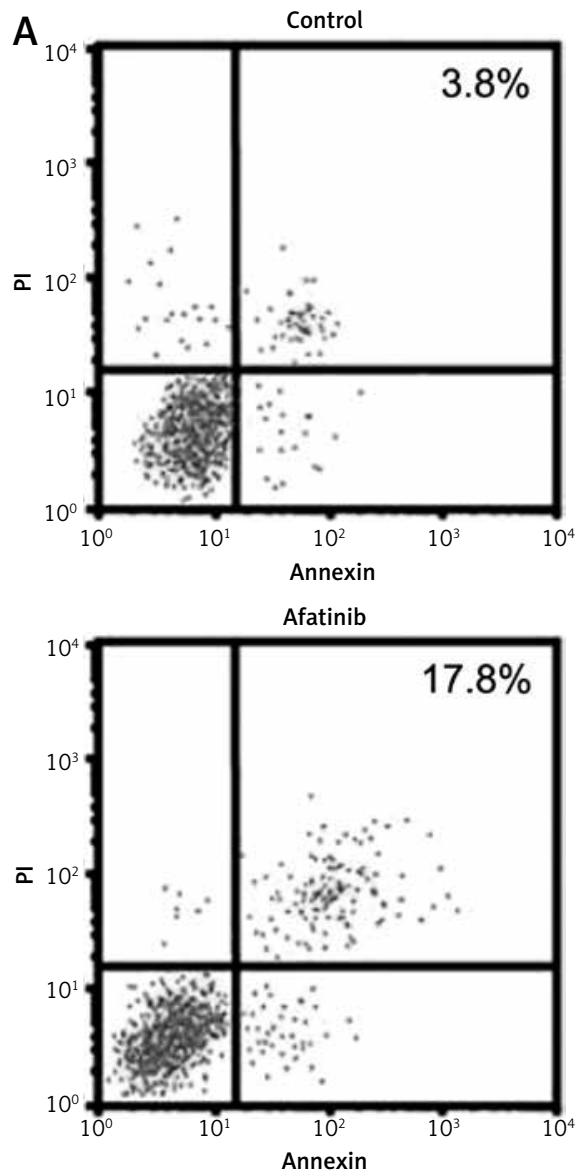

afatinib $(10 \mu M)$ and then examined with Annexin V/PI FC. Afatinib treatment clearly promoted apoptosis in U373 and U87 cells (Figures 2 A, B). Next, apoptosis-related proteins, anti-apoptotic $\mathrm{Bcl}-2$

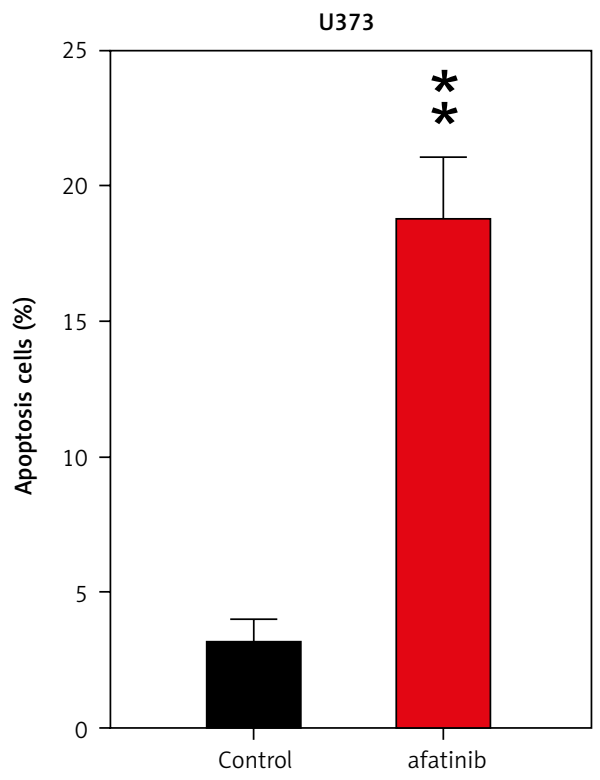

Figure 2. Apoptosis of glioma cells regulated by afatinib. U373 and U87 cells were treated with afatinib $(10 \mu \mathrm{M})$. A, B - Annexin V/PI staining results reveal that afatinib significantly increased the apoptosis rate in both glioma cell lines. The early apoptotic population of cells is indicated in the upper right quadrant of each plot. 
B
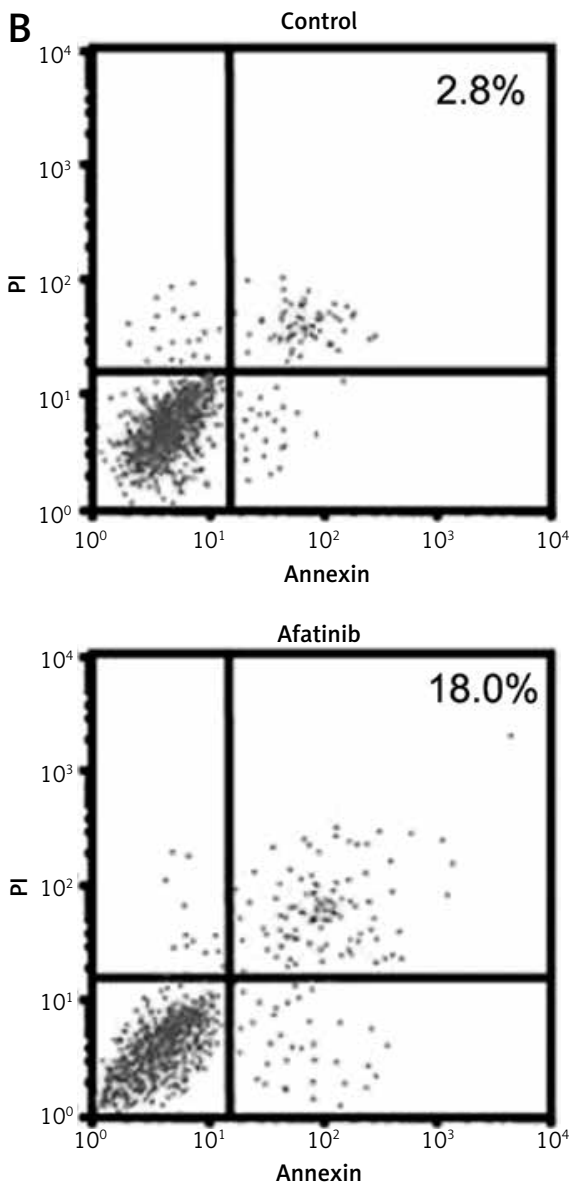

C
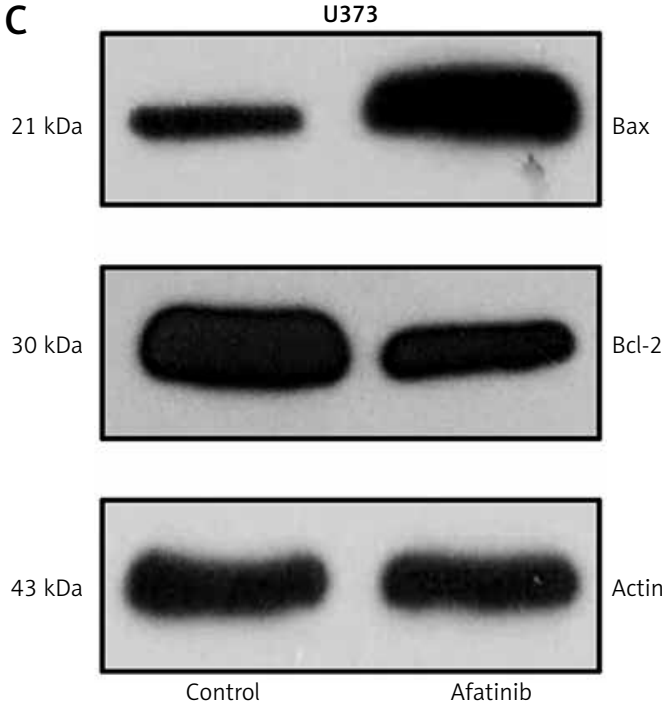

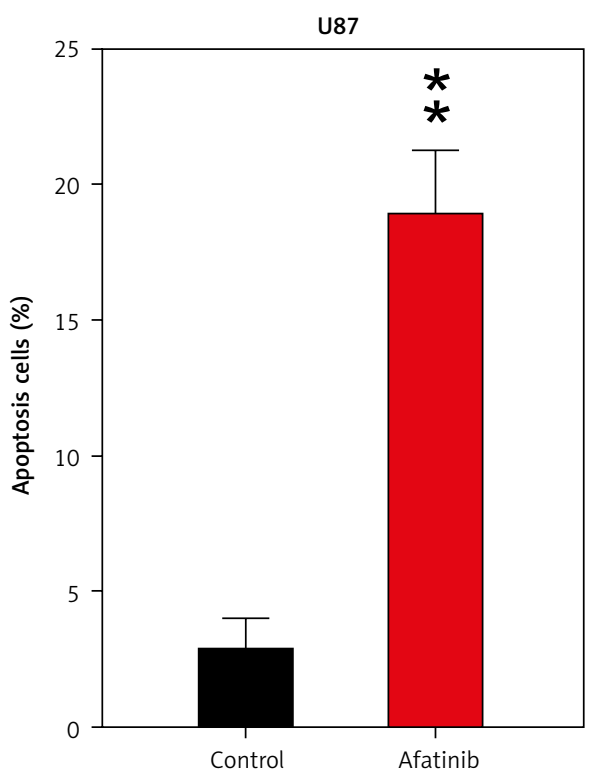

D
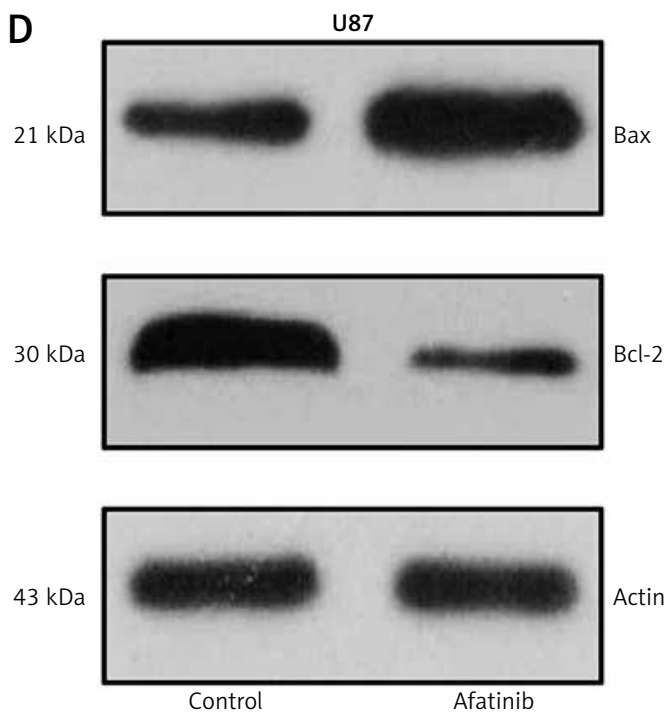

Figure 2. Cont. C, D - Western blotting results reveal that afatinib treatment regulated the expression of $\mathrm{BCl}-2$ and Bax in U373 and U87 cells. $N=3 ;{ }^{* *} p<0.01$ (vs. control group)

and pro-apoptotic Bax, were examined using WB; it was demonstrated that afatinib upregulated the expression of Bax while downregulating $\mathrm{BCl}-2$ ex pression in both the cell lines (Figures 2 C, D).

Moreover, we examined the expression of key pro-apoptotic PUMA expression in both cell lines using afatinib treatment of different concentrations.
Afatinib treatment appeared to elicit PUMA expression in a dose-dependent manner (Figures $3 \mathrm{~A}, \mathrm{~B}$ ).

The role of PUMA in afatinib-induced mediation of cell growth and apoptosis

To investigate the effect of PUMA in the regulation of growth and apoptosis of glioma cells by 
A PUMA

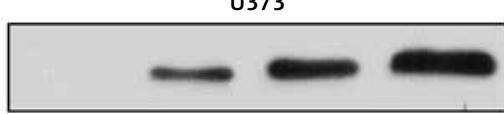

GAPDH

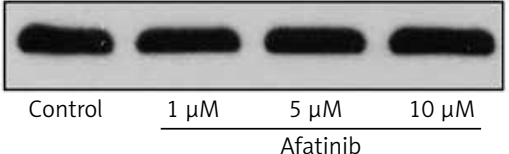

B

$22 \mathrm{kDa}$

$36 \mathrm{kDa}$
PUMA

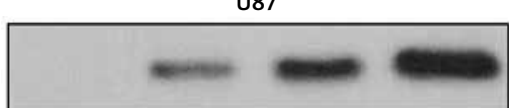

GAPDH

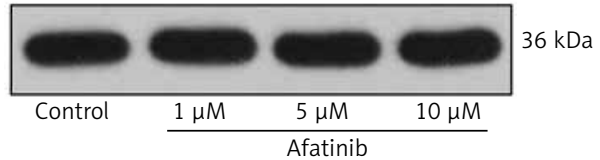

Figure 3. PUMA expression increased by afatinib. U373 and U87 cells were exposed to afatinib with different concentrations $(1,5$, and $10 \mu \mathrm{M})$. A, B - Western blotting was used to show PUMA expression in U373 and U87 cells. $N=3$

A
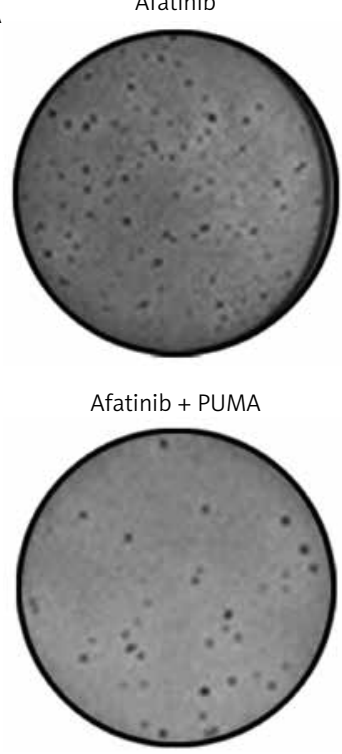

B

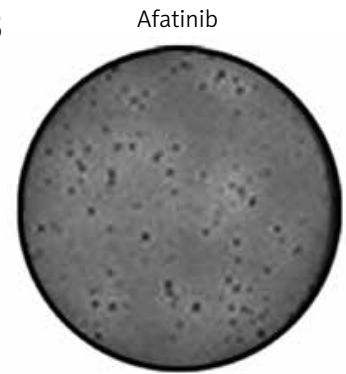

Afatinib + PUMA

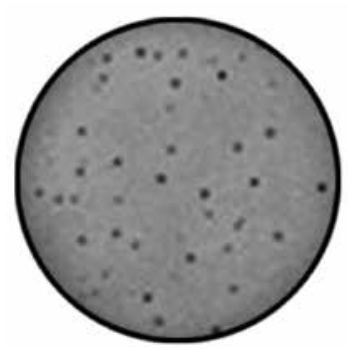

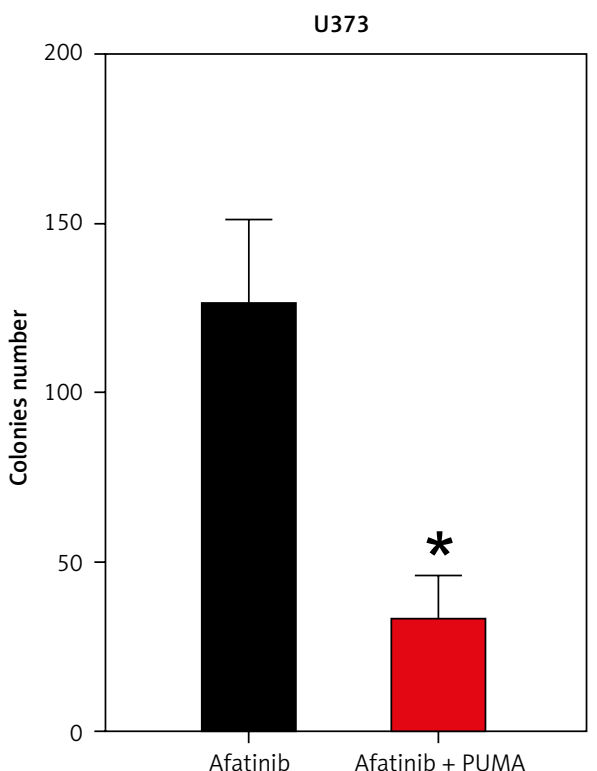

U87

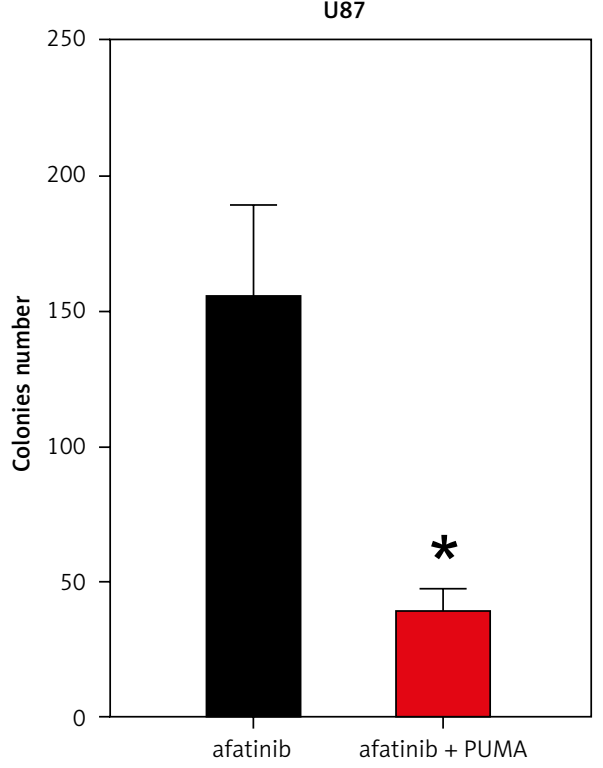

Figure 4. Influence of PUMA overexpression on growth and apoptosis of afatinib-treated glioma cells. U373 and U87 cells with overexpressed PUMA were subjected to $10 \mu \mathrm{M}$ afatinib for 2 days. A, B - Soft agar colony formation assay was utilized to determine the cell number at $48 \mathrm{~h}$ after afatinib treatment. 

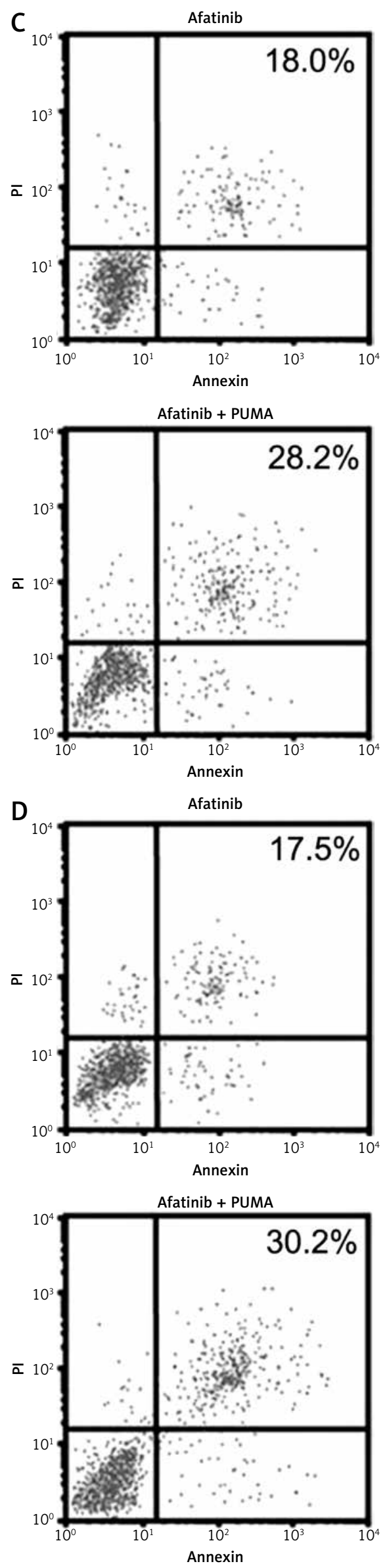
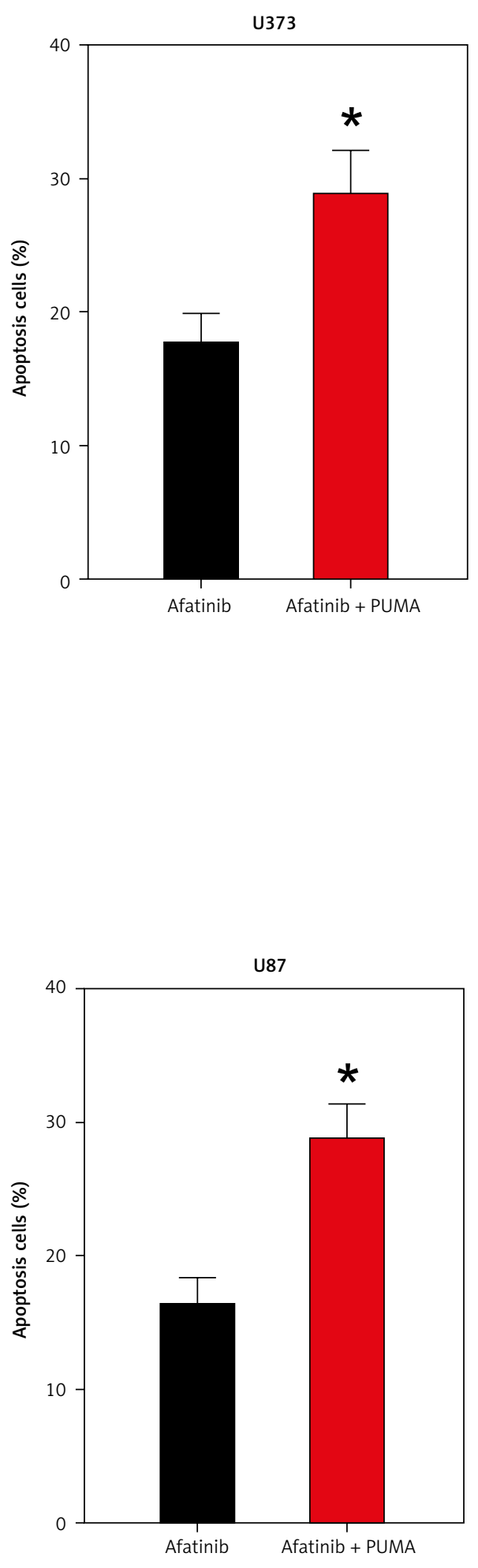

Figure 4. Cont. C, D - Annexin V/PI FC was employed to reveal the apoptosis rate in both glioma cell lines after treatment. The early apoptotic population of the cells is visible in the upper right quadrant of each plot. 
E
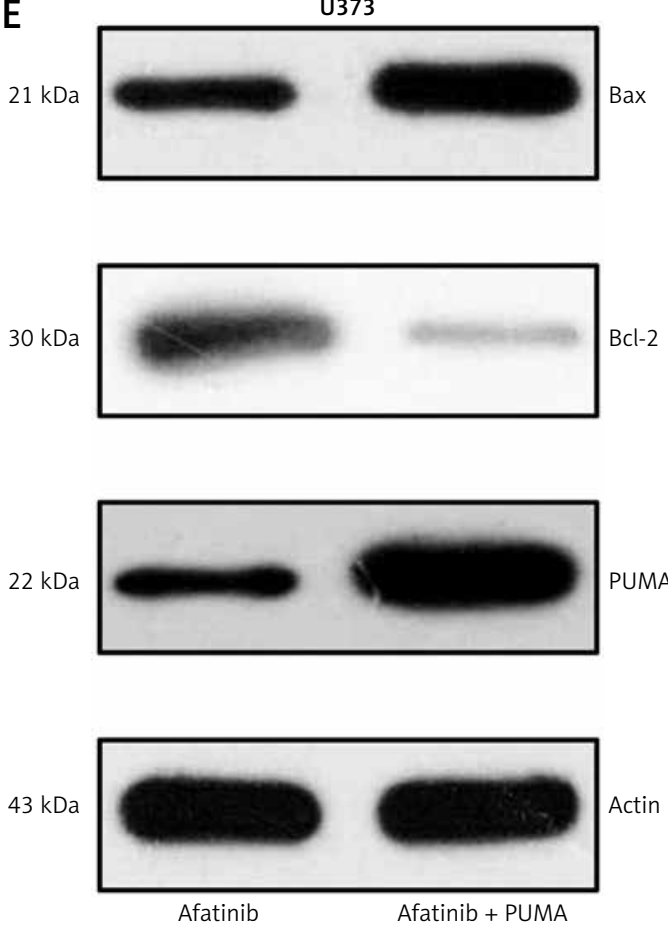

F

$21 \mathrm{kDa}$

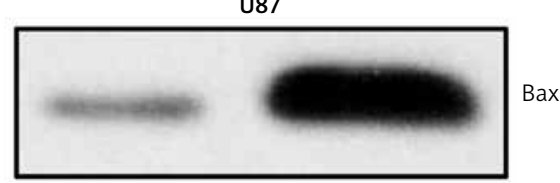

$30 \mathrm{kDa}$

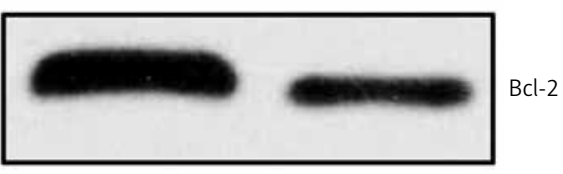

$22 \mathrm{kDa}$

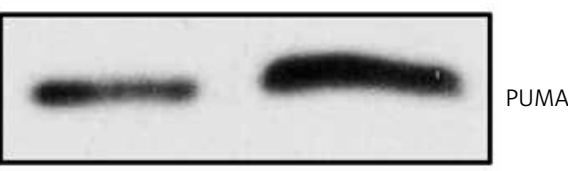

$43 \mathrm{kDa}$

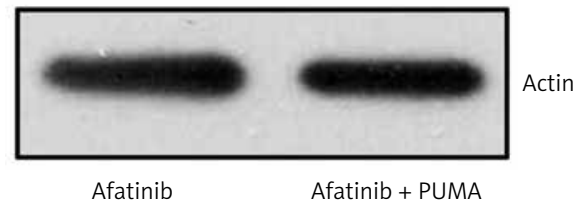

Figure 4. Cont. E, F - Western blotting results reveal that PUMA overexpression regulated the expression of Bcl-2 and Bax in U373 and U87 cells. $N=3 ;{ }^{*} p<0.05$ (vs. indicated group)

afatinib, PUMA was deliberately overexpressed or silenced in the afatinib-treated U373 and U87 cells.

First, the overexpressing cells were investigated. In the PUMA-overexpressing U373 and U87 cells, there was an increase in the inhibition of cell growth caused by afatinib treatment (Figures 4 A, B). Annexin V/PI FC also indicated that PUMA overexpression led to an increase in the number of apoptotic cells induced by afatinib (Figures 4 C, D). Overexpression of PUMA also increased the expression of $\mathrm{Bax}$ and reduced the $\mathrm{Bcl}-2$ level (Figures $4 \mathrm{E}, \mathrm{F}$ ). PUMA was then silenced in afatinib-treated U373 and U87 cells by the transfection of siRNA-PUMA. The colony formation assay showed that silencing PUMA restored the colony number that had been impaired by afatinib in both cell lines (Figures $5 \mathrm{~A}, \mathrm{~B}$ ). Silencing PUMA also reduced the number of apoptotic cells, which were elevated by afatinib treatment (Figures 5 C, D). Additionally, silencing reduced Bax expression and increased $\mathrm{Bcl}-2$ expression in the afatinib-treated U373 and U87 cells (Figures 5 E, F). Altogether, these data indicate that in this study, in vitro afatinib treatment reduced glioma cell growth through PUMA-mediated apoptosis.

\section{Reduction of xenograft tumors through PUMA by afatinib administration}

To further reveal the effect of afatinib and PUMA on glioma xenograft tumors in nude mice, U373-MG cells or U373-MG cells with PUMA knockdown (KD) were injected into the right flanks of female nude mice. The successful KD of PUMA was confirmed by Q-PCR and WB (Figures $6 \mathrm{~A}, \mathrm{~B}$ ). Afatinib administration clearly reduced the tumor weight (Figure $6 \mathrm{C}$ ), and afatinib-treated tumors grew at a significantly slower rate than the vehicle-treated tumors (Figure 6 D). In the KD tumors, the downregulation of PUMA notably reduced the anti-tumor efficiency of afatinib, as evidenced by a restored tumor weight and tumor growth rate (Figures 6 C, D). Additionally, WB data showed that in PUMA KD tumor cells, Bcl-2 expression was higher, whereas Bax expression was lower than those in WT tumor cells (Figure 6 B). Altogether, these data indicate that in vivo afatinib administration reduced xenograft tumors through PUMA.

\section{Discussion}

Aggressive treatment methods involving surgery, radiation therapy, and/or temozolomide fail to considerably improve the chances of survival for patients with glioblastoma [24]. Most patients with glioblastoma are troubled by recurrence, which contributes to the universal fatality, indicating that it is imperative to investigate the disease and develop new therapies that increase survival rates. This study explored the potency of afatinib in glioma cell culture and mouse models and found that afatinib suppressed the proliferation and survival of glioma cells in a dose-dependent manner through the induction of cell apoptosis. Moreover, afatinib treatment also increased PUMA 
A
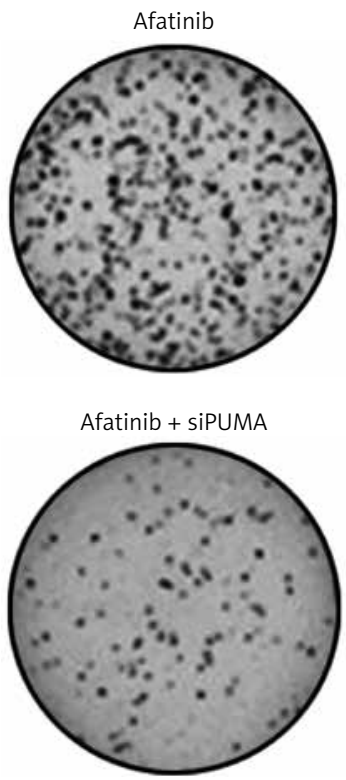

B
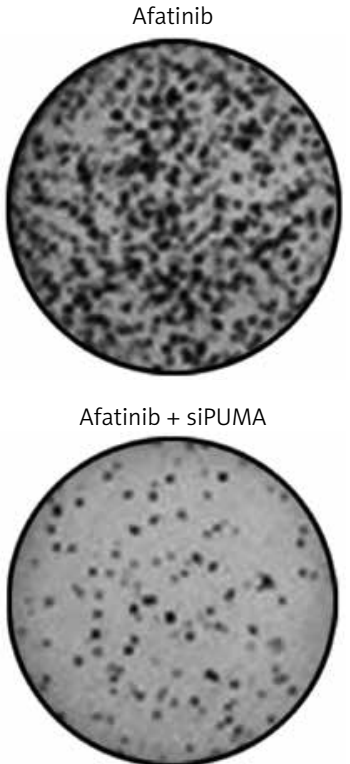

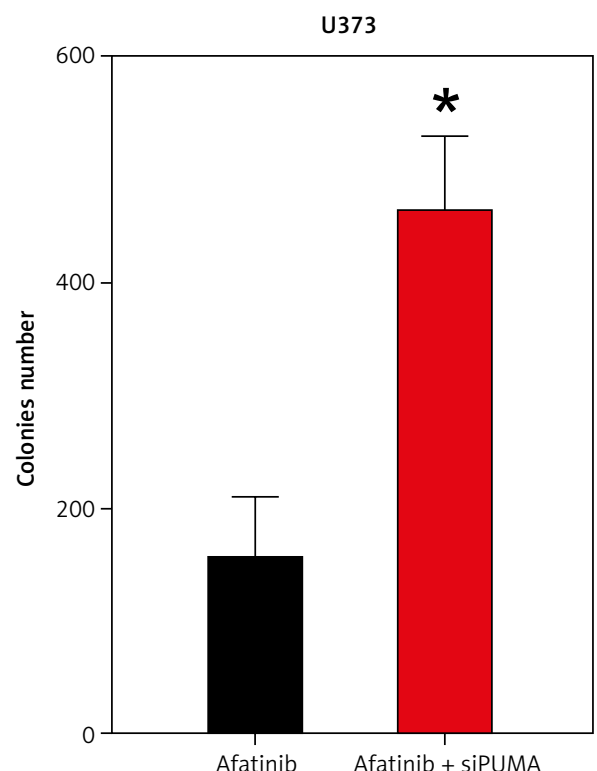

U87

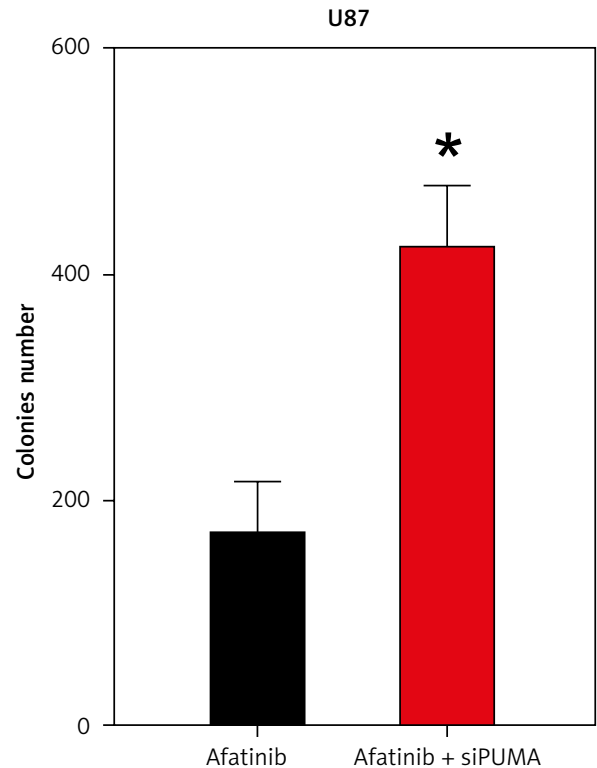

Figure 5. Influence of PUMA silencing on growth and apoptosis of afatinib-treated glioma cells. U373 and U87 cells with silenced PUMA were treated with $10 \mu \mathrm{M}$ afatinib for 2 days. A, B - Soft agar colony formation assay was used to detect the number of cells at $48 \mathrm{~h}$ after afatinib treatment.

expression in treated cells. Overexpression and silencing of PUMA in glioma cells further affected the pro-apoptotic effect of afatinib, promoting and counteracting it, respectively. Remarkably, our in vivo study indicates that afatinib may repress tumor growth and trigger apoptosis via PUMA in xenograft tumor mouse models. However, only one cell line, U373, was used in the animal experiment; that is because we failed to carry out the xenograft model in mice with U87 cells in three independent experiments.

Previous reports have indicated that afatinib displays synergistic cytotoxicity with other compounds in diverse cancer cells [25-27]. Afatinib monotreatment has also been reported to induce apoptosis in non-small-cell lung carcinoma (NSCLC) cell lines [23], head and neck squamous cell cancer [28], neuroblastoma [29], bladder cancer [30], and retinoblastoma [31]. Therefore, we aimed to determine whether single afatinib treatment leads glioma cells to death. In this study, we found that afatinib significantly increased the apoptotic cell number in two glioma cell lines in a dose-dependent manner. Moreover, PUMA expression was demonstrated to be involved in afatinib-mediated cell death in vivo and in vitro. These findings indicate an explanation for the underlying mechanism of the effect of afatinib administration on tumor 

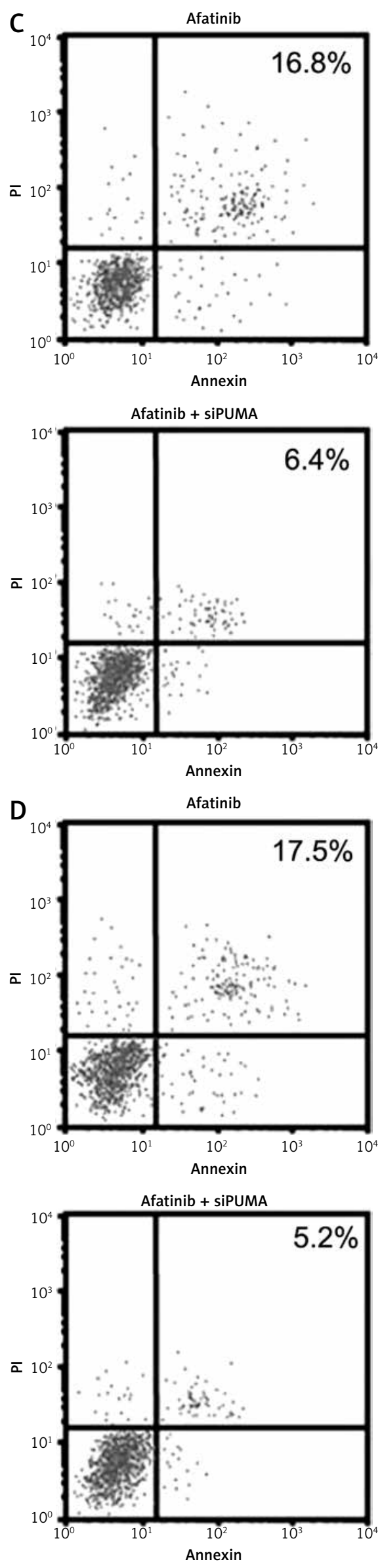
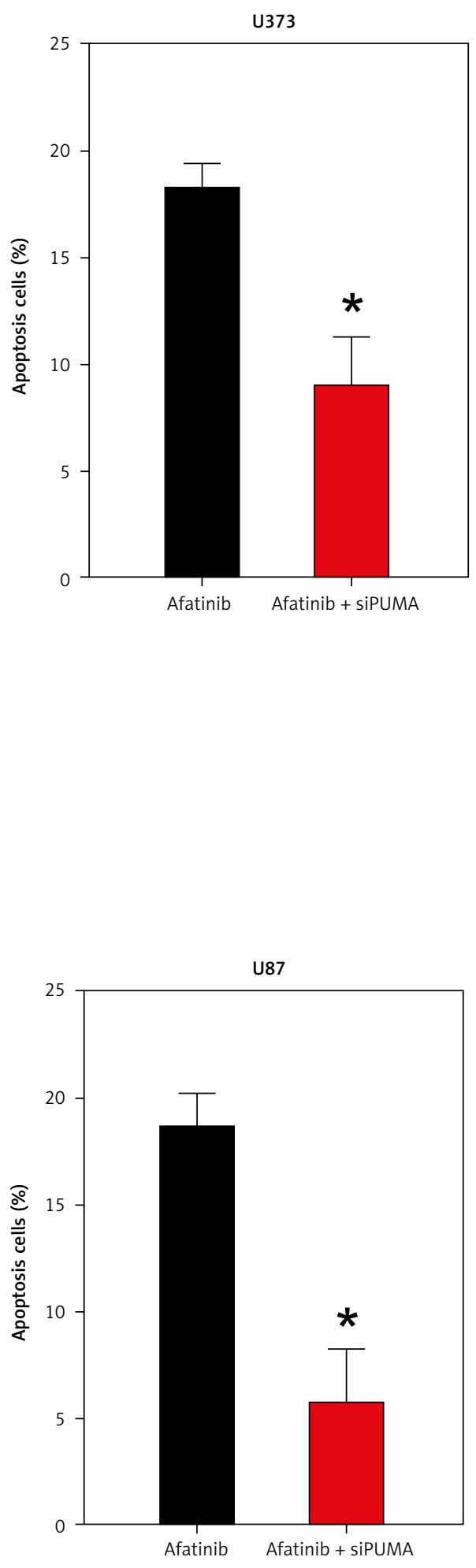

Figure 5. Cont. C, D - Annexin V/PI FC was employed to reveal the apoptosis rate in both glioma cell lines after treatment. The early apoptotic population of the cells is visible in the upper right quadrant of each plot. 
E

$21 \mathrm{kDa}$

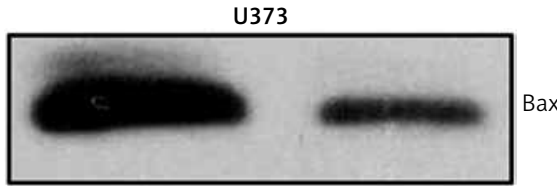

$30 \mathrm{kDa}$

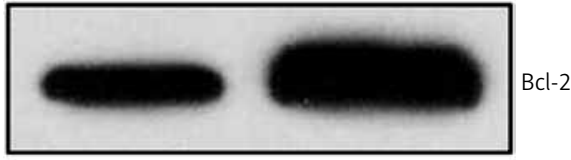

$22 \mathrm{kDa}$

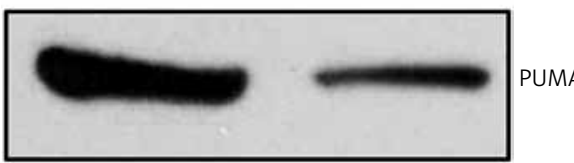

43 kDa

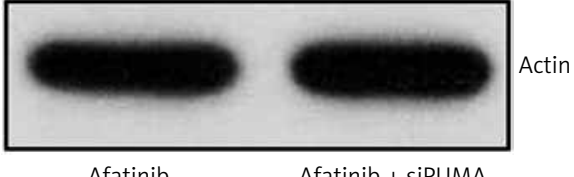

$\mathrm{F}$

$21 \mathrm{kDa}$

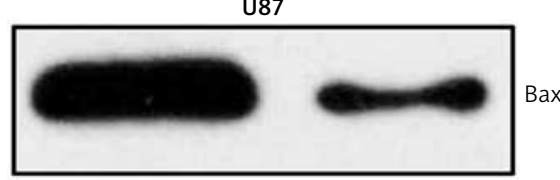

$30 \mathrm{kDa}$

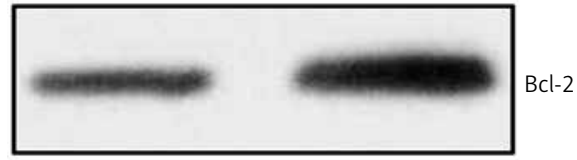

$22 \mathrm{kDa}$

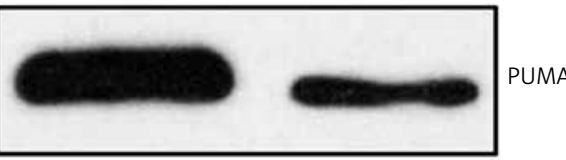

$43 \mathrm{kDa}$

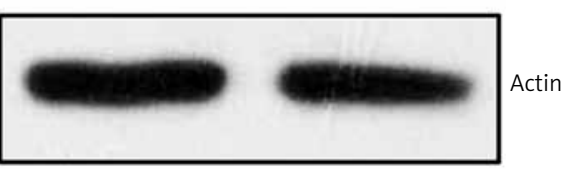

Afatinib

Afatinib + siPUMA

Figure 5. E, F-Western blotting results reveal that PUMA silencing regulated the expression of Bcl-2 and Bax in U373 and U87 cells. $N=3 ;{ }^{*} p<0.05$ (vs. indicated group)

cell death and suggest that afatinib is still an effective compound for glioma therapy.

PUMA is a member of the BH3-only subgroup of the Bcl-2 family; once transactivated by $\mathrm{p} 53$, it triggers apoptosis to respond to genotoxic

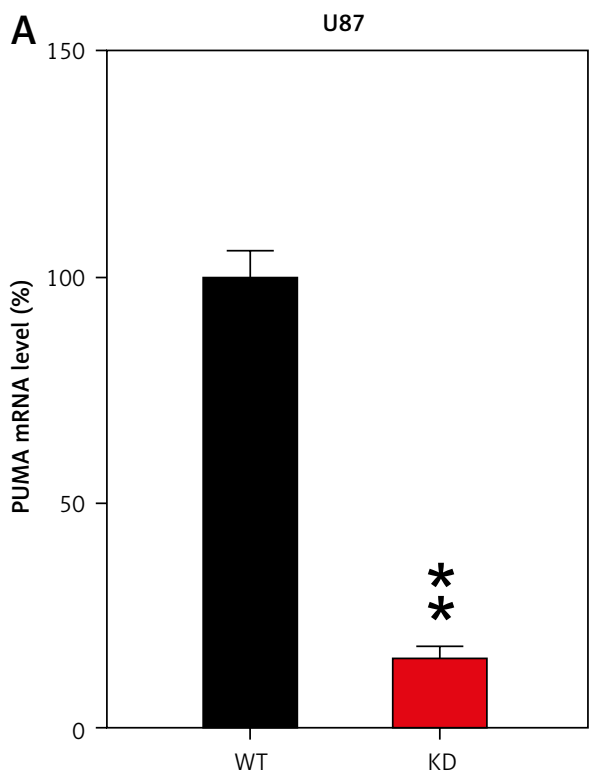

Figure 6. Influence of afatinib administration on wild type (WT) and PUMA knockdown mouse xenograft tumors. U373-MG cells with PUMA knockdown (KD) or control cells were subcutaneously injected in nude mice $(n=6)$. A - Quantitative PCR revealed the mRNA expression of PUMA in WT and PUMA knockdown mouse xenograft tumors. B - Western blotting showed the protein expression of PUMA, Bcl-2, and Bax in WT and PUMA knockdown mouse xenograft tumors. stresses [32]. Once stimulated by non-genotoxicity stress, such as ischemia/reperfusion and cytokine/growth factor loss, PUMA is activated by other transcription factors to elicit p53-independent apoptosis [33]. Biochemical studies indicate

B
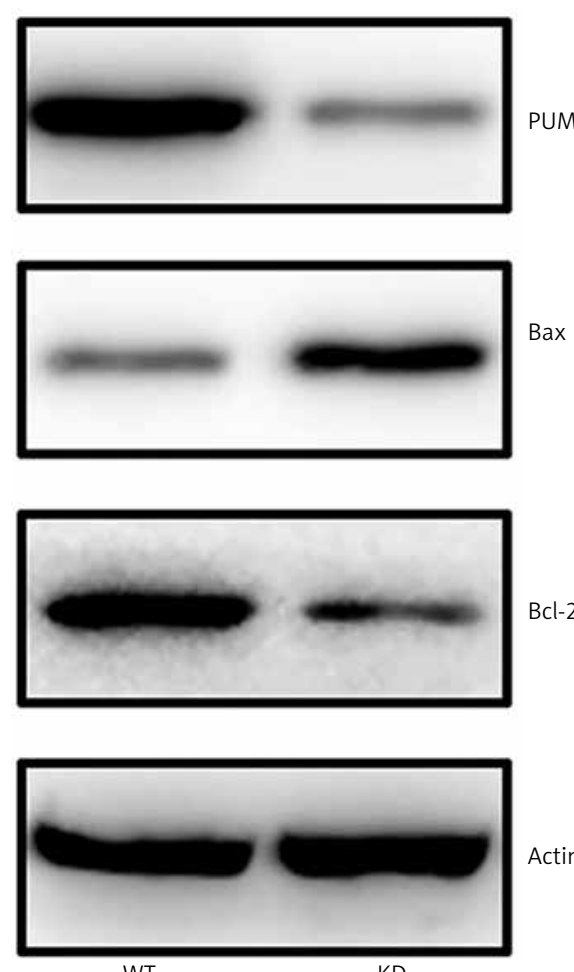

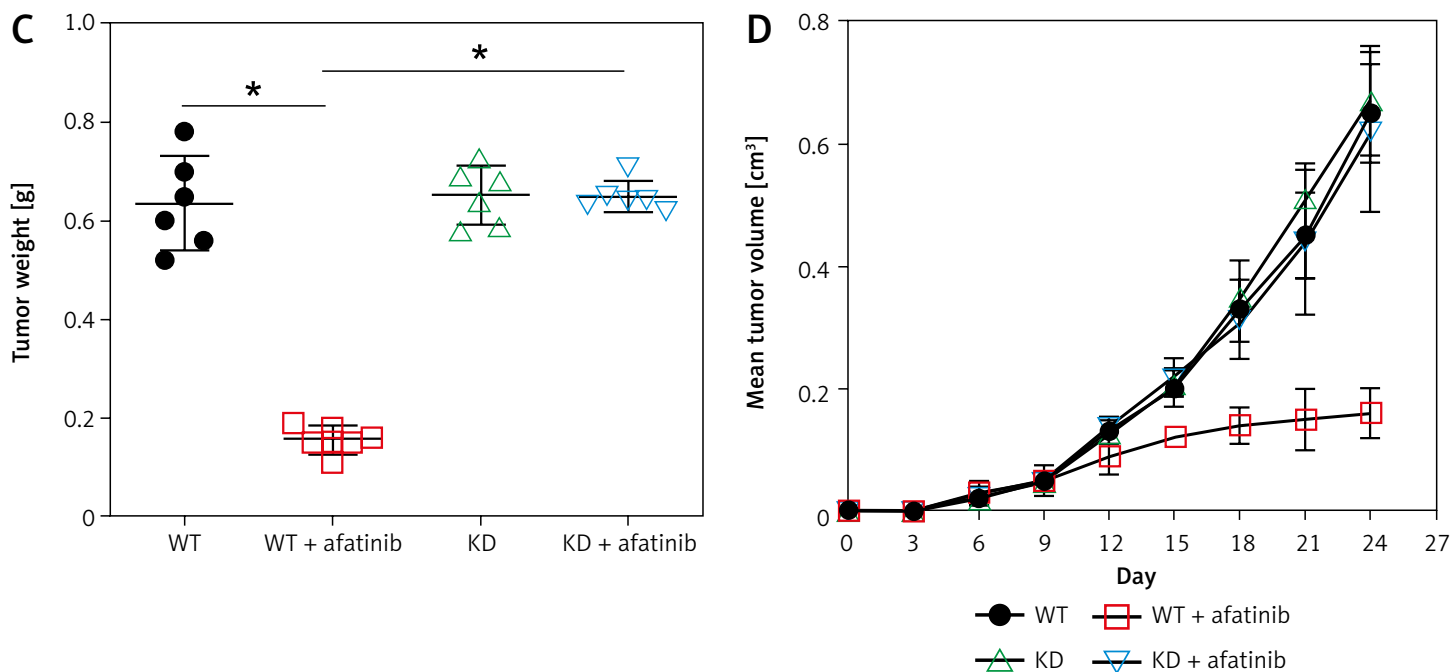

Figure 6. Cont. C - Xenograft tumor weight was determined 25 days after injection. D - Tumor growth curve at $0-24$ days after injection. $N=3 ;{ }^{*} p<0.051 ;{ }^{* *} p<0.01$ (vs. control group)

that genotoxicity and non-genotoxicity could contribute to the triggering of apoptosis by PUMA through the interaction of Bak and/or Bax with other Bcl-2 family members, thereby damaging mitochondria and activating caspase [34]. In our study, both Q-PCR and WB assay showed that afatinib treatment could upregulate PUMA in glioma cell lines. Ectopic PUMA overexpression augmented the pro-apoptotic effects of afatinib in glioma cells, whereas PUMA silencing abated the effect of afatinib. Afatinib administration caused a reduction of tumor size in xenograft mice, whereas PUMA knockdown decreased the effect of afatinib treatment on tumor growth in vivo.

In conclusion, this work confirms that afatinib administration dramatically reduces the proliferation and apoptosis of triggered glioma cell lines in vitro and significantly suppresses tumor growth in xenograft models. Afatinib dramatically decreased tumor size in xenografts in our mouse models through the induction of cell death. This study warrants further investigation into the mechanism of afatinib in glioblastoma treatment.

\section{Conflict of interest}

The authors declare no conflict of interest.

\section{References}

1. Bertoni APS, Iser IC, de Campos RP, Wink MR. Normalization in human glioma tissue, in quantitative real-time PCR. Springer 2020; 2065: 175-90.

2. Ding Y, Wang X, Pan J, et al. Aberrant expression of long non-coding RNAs (IncRNAs) is involved in brain glioma development. Arch Med Sci 2020; 16: 177-88.

3. Eyler CE, Foo WC, LaFiura KM, McLendon RE, Hjelmeland $A B$, Rich JN. Brain cancer stem cells display preferential sensitivity to Akt inhibition. Stem Cells 2008; 26: 3027-36.

4. Geiger GA, Fu W, Kao GD. Temozolomide-mediated radiosensitization of human glioma cells in a zebrafish embryonic system. Cancer Res 2008; 68: 3396-404.
5. Zheng Y, Lin L, Zheng Z. TGF- $\alpha$ induces upregulation and nuclear translocation of Hes1 in glioma cell. Cell Biochem Funct 2008; 26: 692-700.

6. Dungo RT, Keating GM. Afatinib: first global approval. Drugs 2013; 73: 1503-15.

7. Solca F, Dahl G, Zoephel A, et al. Target binding properties and cellular activity of afatinib (BIBW 2992), an irreversible ErbB family blocker. J Pharmacol Exp Ther 2012; 343: 342-50.

8. Li D, Ambrogio L, Shimamura T, et al. BIBW2992, an irreversible EGFR/HER2 inhibitor highly effective in preclinical lung cancer models. Oncogene 2008; 27: 4702-11.

9. Sequist LV, Yang JC-H, Yamamoto N, et al. Phase III study of afatinib or cisplatin plus pemetrexed in patients with metastatic lung adenocarcinoma with EGFR mutations. J Clin Oncol 2013; 31: 3327-34.

10. Wu Y-L, Zhou C, Hu C-P, et al. Afatinib versus cisplatin plus gemcitabine for first-line treatment of Asian patients with advanced non-small-cell lung cancer harbouring EGFR mutations (LUX-Lung 6): an open-label, randomised phase 3 trial. Lancet Oncol 2014; 15 213-22.

11. Schuler M, Wu Y-L, Hirsh V, et al. First-line afatinib versus chemotherapy in patients with non-small cell lung cancer and common epidermal growth factor receptor gene mutations and brain metastases. J Thorac Oncol 2016; 11: 380-90.

12. Soria J-C, Felip E, Cobo M, et al. Afatinib versus erlotinib as second-line treatment of patients with advanced squamous cell carcinoma of the lung (LUX-Lung 8): an open-label randomised controlled phase 3 trial. Lancet Oncol 2015; 16: 897-907.

13. Hoffknecht P, Tufman A, Wehler T, et al. Efficacy of the irreversible ErbB family blocker afatinib in epidermal growth factor receptor (EGFR) tyrosine kinase inhibitor (TKI)-pretreated non-small-cell lung cancer patients with brain metastases or leptomeningeal disease. J Thorac Oncol 2015; 10:156-63.

14. Reardon DA, Nabors LB, Mason WP, et al. Phase I/randomized phase II study of afatinib, an irreversible ErbB family blocker, with or without protracted temozolomide in adults with recurrent glioblastoma. Neuro Oncol 2014; 17: 430-9.

15. Alshami J, Guiot M-C, Owen S, et al. Afatinib, an irreversible ErbB family blocker, with protracted temozolomide 
in recurrent glioblastoma: a case report. Oncotarget 2015; 6: 34030-7

16. Vengoji R, Macha MA, Nimmakayala RK, et al. Afatinib and Temozolomide combination inhibits tumorigenesis by targeting EGFRvIII-cMet signaling in glioblastoma cells. J Exp Clin Cancer Res 2019; 38: 266.

17. Han J, Flemington $C$, Houghton $A B$, et al. Expression of bbc3, a pro-apoptotic $\mathrm{BH} 3$-only gene, is regulated by diverse cell death and survival signals. Proc Natl Acad Sci U S A 2001; 98: 11318-23.

18. Nakano K, Vousden KH. PUMA, a novel proapoptotic gene, is induced by p53. Mol Cell 2001; 7: 683-94.

19. Yu J, Wang Z, Kinzler KW, Vogelstein B, Zhang L. PUMA mediates the apoptotic response to p53 in colorectal cancer cells. Proc Natl Acad Sci USA 2003; 100: 1931-6.

20. Guo H, He Y, Bu C, Peng Z. Antitumor and apoptotic effects of 5-methoxypsoralen in U87MG human glioma cells and its effect on cell cycle, autophagy and PI3K/ Akt signaling pathway. Arch Med Sci 2019; 15: 1530-8.

21. Yuan Z, Cao K, Lin C, et al. The p53 Upregulated modu lator of apoptosis (PUMA) Chemosensitizes intrinsically resistant ovarian cancer cells to cisplatin by lowering the threshold set by Bcl-x L and Mcl-1. Mol Med 2011; 17: 1262-74.

22. Peng DY, Song H, Liu LB. Resveratrol-downregulated phosphorylated liver kinase B1 is involved in senescence of acute myeloid leukemia stem cells. J Huazhong Univ Sci Technolog Med Sci 2015; 35: 485-9.

23. Chao T-T, Wang C-Y, Chen Y-L, et al. Afatinib induces apoptosis in NSCLC without EGFR mutation through Elk-1-mediated suppression of CIP2A. Oncotarget 2015; 6: 2164-79.

24. Stupp R, Mason WP, Van Den Bent MJ, et al. Radiotherapy plus concomitant and adjuvant temozolomide for glioblastoma. N Engl J Med 2005; 352: 987-96.

25. Watanuki Z, Kosai H, Osanai N, et al. Synergistic cytotoxicity of afatinib and cetuximab against EGFR T790M involves Rab11-dependent EGFR recycling. Biochem Biophys Res Commun 2014; 455: 269-76.

26. Ioannou N, Seddon AM, Dalgleish A, Mackintosh D, Modjtahedi $\mathrm{H}$. Treatment with a combination of the ErbB (HER) family blocker afatinib and the IGF-IR inhibitor, NVP-AEW541 induces synergistic growth inhibition of human pancreatic cancer cells. BMC Cancer 2013; 13: 41.

27. Chen G, Noor A, Kronenberger P, Teugels E, Umelo IA, De Greve J. Synergistic effect of afatinib with su11274 in non-small cell lung cancer cells resistant to gefitinib or erlotinib. PLoS One 2013; 8: e59708.

28. Liu X, Lv Z, Zou J, et al. Afatinib down-regulates MCL-1 expression through the PERK-elF2 $\alpha$-ATF4 axis and leads to apoptosis in head and neck squamous cell carcinoma. Am J Cancer Res 2016; 6: 1708-19.

29. Mao X, Chen Z, Zhao Y, et al. Novel multi-targeted ErbB family inhibitor afatinib blocks EGF-induced signaling and induces apoptosis in neuroblastoma. Oncotarget 2017; 8: 1555-68

30. Tang Y, Zhang X, Qi F, et al. Afatinib inhibits proliferation and invasion and promotes apoptosis of the T24 bladder cancer cell line. Exp Ther Med 2015; 9: 1851-6.

31. Zhan W-J, Zhu J-F, Wang L-M. Inhibition of proliferation and induction of apoptosis in RB116 retinoblastoma cells by afatinib treatment. Tumour Biol 2016; 37: 9249-54.

32. Yu J, Zhang L. No PUMA, no death: implications for p53-dependent apoptosis. Cancer Cell 2003; 4: 248-9.

33. Yu J, Zhang L. PUMA, a potent killer with or without $\mathrm{p} 53$. Oncogene 2008; 27: S71-83.
34. Edwards AL, Gavathiotis E, LaBelle JL, et al. Multimodal interaction with $\mathrm{BCL}-2$ family proteins underlies the proapoptotic activity of PUMA BH3. Chem Biol 2013; 20: 888-902. 